\title{
Analysis of Web-based Teaching and Personnel Training in Colleges and Universities
}

\author{
Yu Wang \\ Tianfu College of Swufe, Mianyang, 621000, China \\ wangyu1706@126.com
}

Keywords: Web-based Teaching, Colleges and Universities, Personnel Training.

\begin{abstract}
Colleges and universities are cradles of talents with innovative mind, providing many outstanding people to various fields in the society. In recent years, colleges and universities have carried out reforms in teaching philosophy, major setting and content, gaining good results. The reforms allow personnel in colleges and universities to realize their self-fulfillment in various fields and lay a solid intellectual foundation for national economic development. As a totally new teaching model, web-based teaching, which is flexible and intuitive, is built on technologies such as data and Internet. It can change the dull and monotonous model of teaching into vivid ones and arouse students' interests in participating, thinking and exploring, in order to enhance the effectiveness of personnel training in colleges and universities. Starting from the development history of web-based teaching and personnel training, this paper analyzes the opportunities and challenges, which Internet technology and education might confront, and then specifically introduces the existing web-based teaching methods. And finally, based on the web-based teaching, this paper puts forward relevant measures in personnel training in colleges and universities in order to provide more supports for teaching reforms in colleges and universities.
\end{abstract}

\section{Introduction}

At present, China has made great achievements in education reform, but also faces lots of big challenges ahead. As education becomes more and more universal, there emerges an increasingly prominent conflict between good education resources and its demand, thus triggering a series of problems like education quality and equality. There are also problems in group demands and education system levels, etc. China is committed to education equality which can make every citizen constantly improve and perfect themselves in a study-oriented society and become a useful person for the society in a real sense. Given this reality, the integration of web-based teaching and personnel training in colleges and universities can be efficient in pushing our education into a new development phase, resolving education conflicts, balancing interests between stakeholders and constantly improving the efficiency of personnel training, thus realizing a whole lift of people's quality.

\section{Web-based teaching brings development opportunities and challenges to personnel training in colleges and universities.}

The development opportunities web-based teaching brings to personnel training in colleges and universities.

\subsection{Expanding good resources}

The appearance and spread of web-based teaching has positive significance in alleviating education conflicts. In particular, under the trend of digitalized knowledge, web-based teaching platforms like IMOOC and Micro Learning Resource develop quickly, making all learners have access to good resources through the internet. Learners can make use of free resources according to their own needs, strengthen their weakness and improve their study efficiency. The spirit of sharing 
is what the Internet advocates. As compared with traditional education, web-based teaching can transcend the limitations of space and time. Web-based teaching can deliver no matter classes by famous teachers or high-quality classes through the Internet achieve efficient integration and meet the demands of people for high quality education. Coursera is a free, huge and public online project which cooperates with 12 colleges and universities. The number of students from all over the world who apply for this course has reached 1.5 million. Coursera is able to provide rich resources for leaners.

\subsection{Promoting education equality}

Guided by the principle of promoting equality through efficiency, web-based teaching puts limited resources into developing online courses. By improving policies like education sharing policy, web-based teaching reflects the principle of equal education in the second allocation of good education resources. Obviously, web-based teaching can balance resources distribution, provide a study platform suitable for college students, improve the efficiency of personnel training in colleges and universities and at the same time accelerate the development of study-oriented society in China. MOOC in Chinese universities is an example, which provides an opportunity for the public to receive reduction and acquire certificate. Such method improves academic completion.

\subsection{Improving international education standard}

In the new age of globalization when personnel and material flow around the world and the interconnection between nations and regions becomes closer and closer, education gradually becomes a factor in competence on the international stage. Personnel training are at the core of colleges and universities development. As curriculum system and teaching results are more and more concerned, it is of great importance to improve personnel training [1]. Web-based teaching can promote the cross-regional flow and sharing of courses and teaching material and radically change traditional teaching way. By bringing in web-teaching technology, China can further optimize existing education resources and constantly improve international education standard. Take Audacity, a cloud "Silicon Valley University" as an example, which allows students to follow the leaders in Silicon Valley to learn the most required professional skills in the industry and acquire certificate launched by global leading companies such as Google, Facebook and Amazon so as to enhance connection with the industry and the world.

\section{The challenges of web-based teaching brings to personnel teaching in colleges and universities}

\subsection{Impacting traditional view}

Web-based teaching greatly impacts traditional view. Under the principle of teaching students in accordance with their aptitude, colleges and universities respect each student's difference and fundamentally abandon the stereotyped "Duck-stuffing” type of teaching. With the support of the Internet, students and teachers can interact more and self-study is launched and students can study by using fragmented time, anytime and anywhere.

\subsection{Impacting teachers}

The Internet has infiltrated into people's everyday life. People can now gain information faster in a wider way. Students can acquire knowledge not only from teachers but also in other various ways. Talent training in colleges and universities is no longer one-way but two-way even multi-way interaction and brings great challenges to knowledge authority and monopoly. The actual function of education is also being doubted. The most obvious change is the change of teachers' role. First, teachers are no longer a person who imparts knowledge but a study partner with students who needs to organize and guide them [2]. Second, the knowledge structure of teachers is impacted. Third, teachers are divided by their own abilities into lecturer (good at teaching), research instructor (good at research) and tutor (mainly instructs and supervises students to finish their assignments). 


\subsection{Impacting teaching mode}

The traditional teaching mode is centered on teachers while students are always in a passive position. The lack of interaction between students and teachers makes teaching results not so ideal. The appearance of web-based teaching gave birth to new-type teaching modes like IMOOC and extends study from class to outside class, making traditional teaching no longer suitable for students.

\subsection{Impacting personnel training mode}

Web-based teaching brings about the change of teaching and study method and impacts the traditional personnel training mode in colleges and universities [3]. For example, personnel training in colleges and universities can't be away from market needs. It should put in place diversified personnel training mode like credit system and flexible study system, etc. At the same time, colleges and universities should optimize major structure and adjust department setting according to the trend of economic and social development. University gradually becomes a student society where students live and socialize here. The content of learning can be at any school and from any course. School will change the assessment method for students and management method.

\section{Analysis of existing web-based teaching methods}

\subsection{Micro learning Resource}

Micro learning is a kind of digital resource, which utilizes information technology to deal with small units of learning content and process according to cognition rule of students. Micro learning is distinctively featured by short time and concise contents which facilitates the recording and learning of students (Figure 1 illustrates the features of micro learning). Compared with the application of it in colleges and universities abroad, micro learning operates with a lag in China. It is mainly because most of the teachers have not explored the micro learning methods in a systematic way. Moreover, they have devoted little time to making it due to their extremely heavy teaching tasks at school, which has negatively influenced the effects of micro learning. Therefore, teachers in colleges and universities should have a good knowledge of the advantages of micro learning and make more micro learning resources in order to offer better resources support for self-learning of the students. Generally speaking, students in colleges and universities have the ability of self-learning. As a result, teachers can divide their students into groups and ask them to watch the micro learning resources outside of class. After watching, students can have a discussion in groups and should report their self-learning results in class. This can not only help teachers have a good knowledge of the learning situations of their students, but also can enhance the efficiency of teaching.

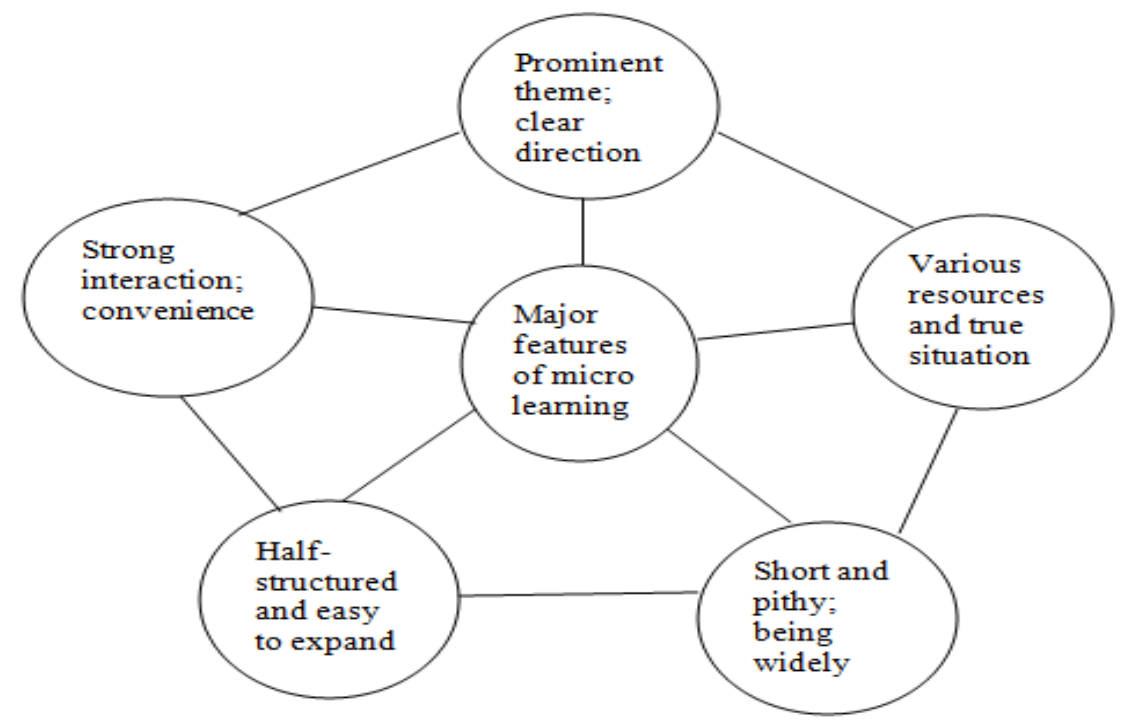

Figure 1 the features of micro learning 


\subsection{Cloud Computing}

Cloud computing is a product of the interaction and common development of science and technology, specifically referring to the further development of distributed and paralleled processing. It is a kind of network composed of millions of servers, which can provide users with pertinent services. Among them, the network, offering those services, is known as "Cloud". Cloud computing blazes a new trial for personnel training in colleges and universities. By taking advantage of cloud computing, colleges and universities can reduce the input of cost. So, there is no need of purchasing hardware and software infrastructure. [4] What's more, through the cloud computing, teachers and students can no longer face the low-version software and expensive upgrading costs. In practice, colleges and universities can build open information service center to release information for admission, employment and overseas study. Therefore, students and teachers can acquire the first-hand information they want which can avoid the situation of information asymmetry. Through this information service center, colleges and universities, students and society can be integrated as one, which can help achieve the goal of the transparency of educational information and gradually build fine images for colleges and universities. Moreover, besides teaching resources, entertainment and book resources are also included in cloud resources. Users can enjoy the resource sharing through different terminals, which bring more convenience for students' learning.

\subsection{Multi-media Technology}

Based on the computer, the multi-media technology firstly starts from the 1990s, which has assembled texts, graphics, animation and so on. Colleges and universities apply multi-media technology to teaching, which can present learning content vividly and randomly and can also arouse their interests for learning and participating in class. The application of multi-media technology in personnel training can improve the training pertinence, respect the distinctiveness and needs of students and consolidate the teaching for difficult knowledge in order to improve the effectiveness of teaching. For example, in the teaching course named "social security system abroad", teachers utilize multi-media technology to foster an immersive studying atmosphere for students, which can help students have further understanding of the political and historical background of foreign social security system. What's more, it can also achieve remarkable teaching results and break through difficult knowledge efficiently.

\subsection{Massive Open Online Course (MOOC)}

Once the MOOC is available in 2008, it has achieved rapid development. Then, MOOC has become increasingly popular in the United States at the year of 2012, which is named as "the Year of MOOC” by media. At that time, Stanford University, Harvard University and MIT have all taken active part in this MOOC fashion. Some representative support platforms for MOOC, such as "openuoED" and "Coursera" have emerged, which can improve the quality of teaching in colleges and universities. In 2013, there also emerged a MOOC fever among Chinese people with both Peking University and Tsinghua University joining the International MOOC League. Based on the level of public welfare, students can enjoy resource sharing with others through this platform, which can meet the "spiritual" needs to the fullest extent. Through MOOC, colleges and universities can achieve fine images in society and enhance their global reputation.

\section{Ways to improve Web-based talent training model}

\subsection{Accelerating teaching reforms}

Education, with the ultimate goal to cultivate well-rounded talents, is essentially different from course education. Developing professionals that meet the need of socio-economic development efficiently embodies the core function of education. In this context, the Internet age expects colleges and universities to strengthen moral education as a way to build students into valuable members of the society amid their effort to imparting professional knowledge and skills. [5] As a 
matter of fact, fine tradition and campus culture of a university will exert invisible yet formative influence on students, boosting their comprehensive quality. Therefore, by no means will school education be replaced by web-based teaching model. Under new circumstances, we should look into the way to make the internet better serve our teaching goal instead of worrying too much about the fate of the school. In the attempt to make talents training more efficient, colleges and universities need to get fully involved in developing the Internet-backed education industry by facilitating exchanges with each other and accelerating teaching reforms.

\subsection{Strengthening educational interaction}

Currently, web-based teaching model such as MOOC and Micro Learning Resource have found their way into higher education practices, contributing much to the orderly teaching marked by proactive interaction between teachers and students. For all impressive results, much remain to be done to get models more connected as a way to make full use of the overall advantage [6]. As a result, online resources including MOOC and Micro Learning Resource should be integrated to combine their strength for better teaching and learning outcomes. Internet-based teaching should serve as a bridge for sound exchanges between teachers and students with the help of modern information technology. We should also be committed to the full integration of Internet and teaching as we seek to involve more and more students in web-based learning activities that will help them with desirable habit of learning. In this way, a learning-oriented society will take shape in China and more quality resources will be shared. Noticeably, if we ignore the importance to boost the interaction and integration among those models, they will be of no value in that they are just the same as online courseware which has been used for more than a decade.

\subsection{Improving evaluation mechanism}

Compared with traditional campus-backed talent training, web-based education suffers from lax standard of admittance, deficient supervision and the lack of incentive mechanism such as a certificate-driven one. Overall speaking, Internet teaching resources available are greatly wasted by students due to their absence of self-discipline and the poor completion of chosen courses. This is why improving the evaluation mechanism is of critical importance. To be specific, a satisfying evaluation mechanism will work to assess students' performance and give the feedback to both teachers and students, which makes it possible to optimize online teaching and enhance learner autonomy. Teachers need to delve deeper into what the benchmark should be and how to make it work based on big data in the attempt to bring the monitoring role of evaluation mechanism into full play and lead higher education to a promising future.

\subsection{Enhancing the operation mechanism}

As market represents a crucial part in China's ongoing commitment to building the socialist market economic system, we should put into consideration the market demand and social requirement in fostering talents to gear intellectual resources to the need of the economic development. Enhancing operation mechanism has a key role to play in meeting this end. Striking the balance between seeking profits and delivering public benefits, and exploring ways to operate MOOC and Micro Learning Resource, which are some viable manners to secure talent building on the right track.

As the credit system of MOOC, which is at its initial stage, is poorly recognized, colleges and universities are expected to organize students and teachers to integrate, classify and evaluate MOOC resources and make a list of those courses based on personnel training system and plan.

On top of that, efforts should be made to boost the recognition of credit by affirming coursecompletion certificate or providing students with the access to college tests. Now, Udacity and Chinese MOOC are implementing the method of issuing of certificates to encourage students to finish their study but still lack of recognition of credit of the society and other universities, which may be the result of the lack of confidence of the society towards the quality of web-based teaching. Therefore, normalizing web-based teaching and acquiring social acceptance can further improve the importance of web-based learning so as to benefit more people. Two approaches can be combined 
to bring more convenience to students, thus raising their performance in Internet-based learning. Put into practice, measures above will be a valuable source of new ideas, leading to exciting achievement in talents training and comprehensive national strength.

\section{Conclusion}

As the Internet technology grows and college teaching reforms spread, the integration of them is an irresistible tide of the time. Down the road, personnel cultivation will stretch beyond the campus and classroom to include the online space, evolving into a comprehensive, open and studentoriented one. Teaching reforms should be carried forward further to cover all students for better sharing of resources and superior quality of teaching. Along the way, we should give full play to the significant part of the Internet in fostering talents by applying sound evaluation and operation mechanism that will inspire students to be successful online learners. With all done, remarkable progress will be made in developing well-rounded talents.

\section{References}

[1] Zhang, Ai ming. The teaching reform of logistics management major in private colleges and the orientation of personnel training. Statistic and Management. 2014(12), 157-158.

[2] Lu Di. The analysis of the demand of mobile internet talents and the current situation of mobile Internet personnel training in colleges and universities. Modern Communication (Journal of Communication University of China). 2015 (06), 141-146.

[3] Zhong Binglin. Web-based teaching and personnel training in colleges and universities. China University Teaching. 2015 (09), 4-8.

[4] Zhang Wenxiang \& Chen Xun. The model and process of news-law inter-disciplinary talents-based on the analysis of the fusion practice of the teaching and research of news dissemination and law discipline in colleges and universities. China University Teaching. 2013 (01), 36-39.

[5] Zeng Erlei \& Tang Suqiong. The study of entrepreneurial personnel training model in China's colleges and universities-based on the case study of national teaching results award. Education Development Study. 2011 (01), 39-42.

[6] Zhang Qing. The SWOT analysis of the cultivation of new foreign trade talents in the application-oriented undergraduate colleges and universities in the "Internet + " era. Journal of YuLin College. 2017 (02), 107-109. 